\title{
The Effects of Topical Agent (Kelo-Cote or Contractubex) Massage on the Thickness of Post-Burn Scar Tissue Formed in Rats
}

\author{
Won Jin $\mathrm{Ko}^{1}$, Young Cheon $\mathrm{Na}^{1,3}$, Bum Sin $\mathrm{Suh}^{1}$, Hyeon A Kim ${ }^{1}$, Woo Hoe Heo ${ }^{1}$, \\ Gum Ha Choi ${ }^{2}$, Seo Ul Lee ${ }^{3}$ \\ Departments of ${ }^{1}$ Plastic and Reconstructive Surgery and ${ }^{2}$ Pathology, Wonkwang University Hospital, Wonkwang University School of \\ Medicine, Iksan; ${ }^{3}$ Wonkwang Institute of Clinical Medicine, Iksan, Korea
}

Background We conducted an experimental study to compare the effect of massage using topical agents (Kelo-cote or Contractubex) on scar formation by massaging the healed burn wound on the dorsal area of Sprague-Dawley (SD) rats.

Methods Four areas of second degree contact burn were made on the dorsal area of each of $15 \mathrm{SD}$ rats, using a soldering iron $15 \mathrm{~mm}$ in diameter. After gross epithelialization in the defect, 15 SD rats were randomly divided into four groups: the Kelo-cote group, Contractubex group, Vaseline group, and control group. Rats in three of the groups (all but the Control group) were massaged twice per day for 5 minutes each day, while those in the Control group were left unattended. For histologic analysis, we performed a biopsy and evaluated the thickness of scar tissue.

Results In the Kelo-cote and Contractubex groups, scar tissue thicknesses showed a significant decrease, compared with the Vaseline and control groups. However, no significant differences were observed between the Kelo-cote and Contractubex groups. In the Vaseline group, scar tissue thicknesses showed a significant decrease, compared with the control groups.

Conclusions The findings of this study suggest that massage using a topical agent is helpful in the prevention of scar formation and that massage only with lubricant (no use of a topical agent) also has a considerable effect, although not as much as the use of a topical agent. Thus, we recommend massage with a topical agent on the post-burn scar as an effective method for decreasing the scar thickness.

Keywords Burns / Cicatrix, hypertrophic / Wound healing / Massage
Correspondence: Young Cheon $\mathrm{Na}$ Department of Plastic and Reconstructive Surgery, Wonkwang University School of Medicine, 895 Muwang-ro, Iksan 570-711, Korea

Tel: +82-63-859-1570

Fax: +82-63-857-3704

E-mail:ycnadr@hanmail.net
This article was supported by Wonkwang University in 2012.

No potential conflict of interest relevant to this article was reported.

\section{INTRODUCTION}

Wound healing is a continuous and complex process that is generally characterized as having three overlapping phases: the inflammatory phase, proliferative phase, and remodeling phase. This process is a series of complex and superbly orchestrated

Copyright (ㅇ 2013 The Korean Society of Plastic and Reconstructive Surgeons

This is an Open Access article distributed under the terms of the Creative Commons Attribution Non-Commercial License (http://creativecommons.org/

licenses/by-nc/3.0/) which permits unrestricted non-commercial use, distribution, and reproduction in any medium, provided the original work is properly cited.

www.e-aps.org 
interactions of cells and mediators, which can be affected by various factors [1]. The proliferative phase is characterized by epithelialization, formation of granulation tissue, neovascularization, wound contraction, and extracellular-matrix reorganization [2]. In normal wound healing, the repair of an open wound terminates with the establishment of a permanent scar consisting mainly of extracellular matrix components such as collagen, fibroblasts, and small vessels. As the wound closes and evolves into a scar, there are important processes: myofibroblast disappearance, the synthesis of extracellular matrix, and replacement with a collagenous matrix. However, dysregulation of these apoptotic phenomena during wound healing is an important cause of excessive scar establishment and development of pathological scarring [3]. Eventually, remaining excess scar tissue may sometimes become the cause of formation of an abnormal scar; this condition is usually treated with the help of a topical application, which helps to cauterize off the excess tissue so as to prevent further proliferation and growth [4].

In wound healing following surgical skin incision, or after inflammation, burns, or trauma, development of flat, flexible scar tissue will normally occur. However, in susceptible individuals, scars can become raised, reddish, and rigid, with itching and pain, and might even lead to serious cosmetic and functional problems for these patients [5].

Several treatments and prevention modalities, such as laser therapy, intralesional agents, cryotherapy, radiation, pressure therapy, occlusive dressings, topical agents, and scar massage, can be used in prevention and treatment of abnormal scars [57]. Topical agents have recently been proposed as the main form of noninvasive treatment and prevention for hypertrophic scars and keloids, and significant improvements have been demonstrated [7-13]. In addition, some surgeons recommend scar massage during the remodeling phase for improvement of aesthetic outcomes [14-17].

We conducted an experimental study to demonstrate the effect of a topical agent (Kelo-cote or Contractubex) in scar formation by massaging the healed burn wound on the dorsal area of Sprague-Dawley (SD) rats. The goal of this experiment was to determine the hydration and massage effects of massage using topical agents on scar formation, when compared to massage using only lubricant without the use of topical agents and leaving scars unattended.

\section{METHODS}

\section{Experimental animals}

The experimental protocol, including the use of animals in the research, was approved by the Institutional Animal Care and
Use Committee, Wonkwang University, Korea.

Fifteen-eight-week-old, 280 to $300 \mathrm{~g}$, male, white SD rats, living under the same conditions were used in the study. Food pellets and water were provided ad libitum throughout the experiment. After the rats had a one-week period of adjustment to the laboratory, we began the study.

\section{Experimental materials}

1) Kelo-cote (A viscous semi-transparent compound, polymerized, minimally cross-linked silicone elastomer. Advanced Bio Technologies, Suwanee, GA, USA).

2) Contractubex (Gel contains the ingredients cepae extract, heparin, and allantoin, MERZ Pharmaceuticals GmbH, Frankfurt/main, Germany).

3) Vaseline (plain petroleum jelly, Unilever Korea, Seoul, Korea).

\section{Wound induction}

For anesthesia, $40 \mathrm{mg} / \mathrm{kg}$ of pentobarbital sodium (Hanlim Pharmaceutical, Seoul, Korea) and $20 \mathrm{mg} / \mathrm{kg}$ of ketamine hydrochloride (Ketar, Yuhan, Seoul, Korea) were injected into the intraperitoneal cavity of the rats. Under aseptic conditions, we removed hair from the dorsal area using an electric shaver and $10 \%$ povidone iodine and $70 \%$ alcohol solution were used for disinfection, followed by application of a soldering iron (the iron tip was cylindrical with a diameter of $1.5 \mathrm{~cm}$ ) at $200^{\circ} \mathrm{C}$ for 10 seconds at the dorsal area, and four areas of skin defects measuring $1.5 \mathrm{~cm}$ in diameter were made. This soldering iron was designed specifically for use in the experiment. In addition, the soldering iron was made with the temperature display and timer. To exclude the wound healing effect of adjacent wound defects, each wound was placed at a distance of $3 \mathrm{~cm}$ between wound defects (Fig. 1).

\section{Wound care}

After gross epithelialization, 15 rats were classified into four groups. The location of each of the four groups was randomized (Table 1). In the Kelo-cote group, the skin defect site was massaged with Kelo-cote twice per day for 5 minutes each day; in the Contractubex group, the skin defect site was massaged with Contractubex twice per day for 5 minutes each day; in the Vaseline group, the skin defect site was massaged with Vaseline twice per day for 5 minutes each day; in the control group, no care was provided for the scars. In groups other than the control group, bare finger massage was performed consistently by one experimenter. Except for the control group, the same volume was applied to each site in the three groups. For comparison of the massage and hydration effects with the control group, we 


\section{Fig. 1. Wound induction and soldering iron}

(A) Wound-induced rat. (B) A soldering iron with a columnar-shaped tip. A soldering iron was used for producing skin defects at $200^{\circ} \mathrm{C}$ for 10 seconds at the dorsal area, and four areas of skin defects measuring $1.5 \mathrm{~cm}$ in diameter were made.
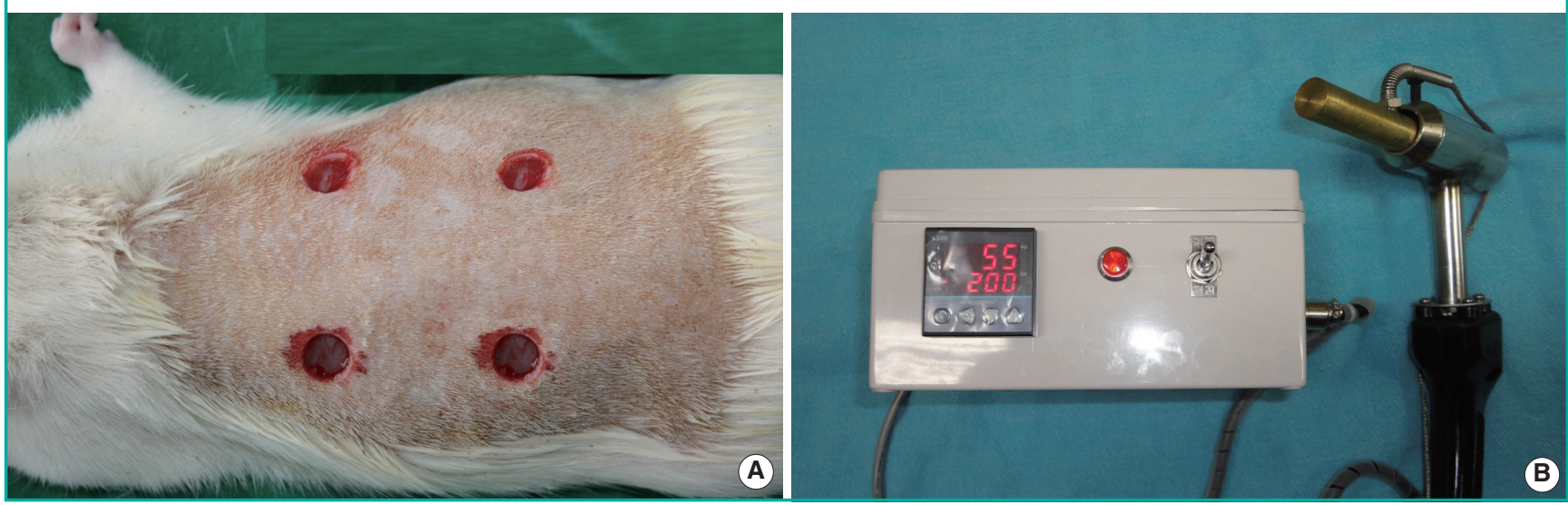

Table 1. Summary of 15 individual experimental rats

\begin{tabular}{|c|c|c|c|c|c|c|}
\hline \multirow{2}{*}{ Animal no. } & \multirow{2}{*}{$\begin{array}{l}\text { Total epithelialization } \\
\text { time (day) }\end{array}$} & \multicolumn{4}{|c|}{ Each group location of the dorsal area } & \multirow{2}{*}{$\begin{array}{c}\text { Biopsy time } \\
\text { (post-massge wk) }\end{array}$} \\
\hline & & Control & Kelo-cote & Contractuvex & Vaseline & \\
\hline 1 & 18 & RU & $\mathrm{RL}$ & LU & $\mathrm{LL}$ & 3 \\
\hline 2 & 20 & LL & RU & $\mathrm{RL}$ & LU & 10 \\
\hline 3 & 22 & LU & LL & $\mathrm{RU}$ & $\mathrm{RL}$ & 17 \\
\hline 4 & 19 & $\mathrm{RL}$ & LU & $\mathrm{LL}$ & $\mathrm{RU}$ & 3 \\
\hline 5 & 19 & $\mathrm{RL}$ & $\mathrm{RU}$ & $\mathrm{LL}$ & LU & 17 \\
\hline 6 & 21 & LU & $R L$ & RU & LL & 10 \\
\hline 7 & 19 & RU & LU & $R L$ & LL & 17 \\
\hline 8 & 20 & RL & LL & RU & LU & 10 \\
\hline 9 & 22 & $\mathrm{RL}$ & $\mathrm{RU}$ & LU & $\mathrm{LL}$ & 3 \\
\hline 10 & 23 & $\mathrm{LL}$ & $\mathrm{RL}$ & $\mathrm{RU}$ & LU & 17 \\
\hline 11 & 20 & LU & $\mathrm{LL}$ & $R L$ & $\mathrm{RU}$ & 10 \\
\hline 12 & 21 & RU & $R L$ & $\mathrm{LL}$ & LU & 17 \\
\hline 13 & 19 & LU & RU & $R L$ & $\mathrm{LL}$ & 3 \\
\hline 14 & 18 & $\mathrm{RL}$ & $\mathrm{RU}$ & LU & $\mathrm{LL}$ & 10 \\
\hline 15 & 23 & $\mathrm{RL}$ & LL & LU & $\mathrm{RU}$ & 3 \\
\hline Mean \pm SD & $20.27 \pm 1.67$ & & & & & \\
\hline
\end{tabular}

created the Vaseline group, because bare finger massage can easily cause skin irritation. In the Vaseline group, Vaseline only was used as a lubricant ointment (Fig. 2).

Rats were placed in cages, one rat per cage, and observed for 17 weeks. During the experiment, feed (5L79, PMI Inc., St. Louis, MO, USA) and water were provided without limitation.

\section{Wound biopsy and histologic examination}

After gross epithelialization, at post-massage week 3, 10, and 17, we selected five rats from each group and took tissue, including scar tissue and tissue from the entire wound site. All of the tissue specimens were fixed in $10 \%$ neutral-buffered formalin for at least 24 hours at room temperature, embedded in paraffin, and sectioned perpendicular to the anterior-posterior axis. Each section was stained with hematoxylin and eosin (H\&E) accord- ing to the standard protocol. The slide sections were evaluated by two pathologists who were blinded to the treatment under a microscope at $40 \mathrm{x}$ magnification. We measured the thickness of the scar tissue in each group by comparison with that of the control group. In the process of measuring the thickness of the scar tissue, the thickness was defined as the depth from the lower border of the basement membrane of the epidermis to the bottom part of dense collagen mesh and fibrosis change. Image J software version 1.47i (National Institutes of Health, Bethesda, MD, USA) was used as the measurement tool.

\section{Statistical analysis}

The results are expressed as mean \pm standard deviation. Based on the result for each group of each date, we compared both the differences of a given group at each point in time and the 


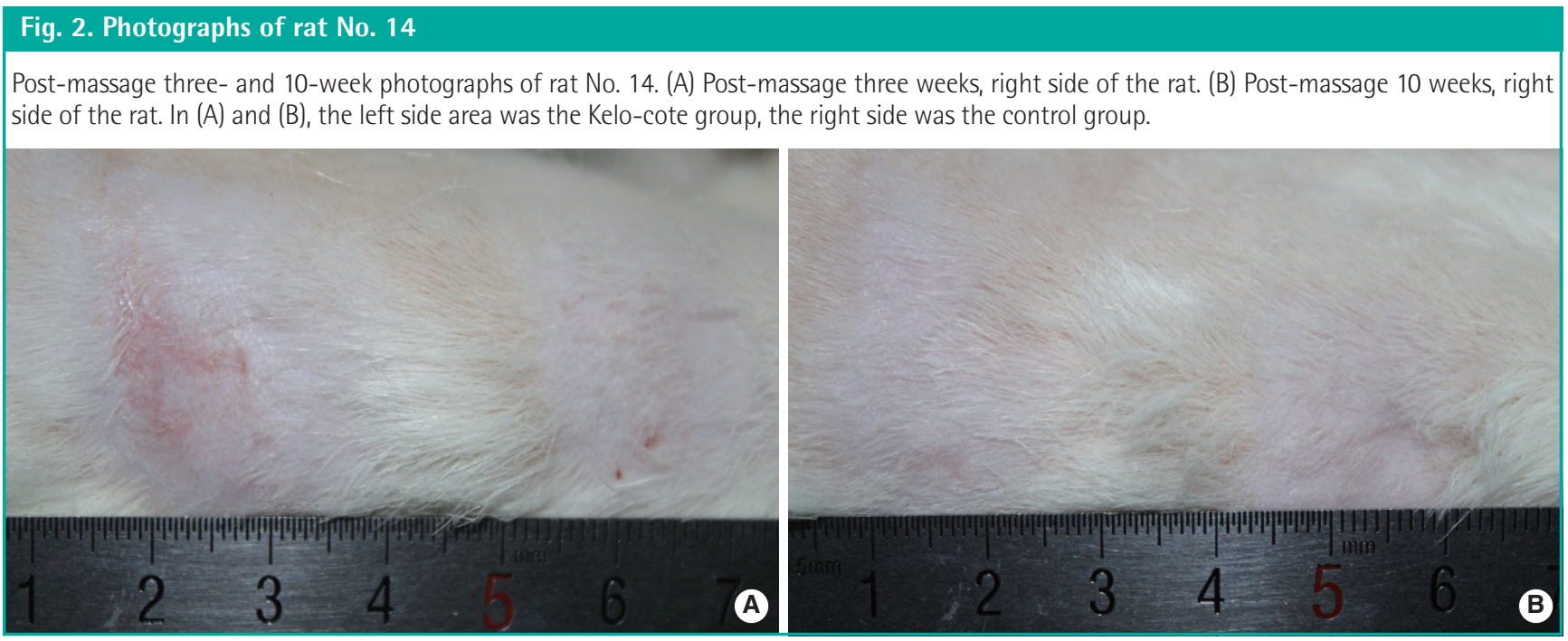

Fig. 3. Histologic evaluation of rat No. 3

(A) Control group. (B) Vaseline group. (C) Kelo-cote group. (D) Contractubex group. Post-massage at 17 weeks after gross epithelialization of rat No. $3(H \& E, \times 40)$. The thickness of scar tissue of the control group (A) was thicker than that of the other groups. The Vaseline group (D) showed a greater thickness than the Kelo-cote group (B) and the Contractubex group (C). However, few differences were observed between the Kelo-cote group (B) and the Contractubex group (C). Black arrow, scar tissue thickness; bar, $20 \mu \mathrm{m}$ length; white capital "s", scar tissue.
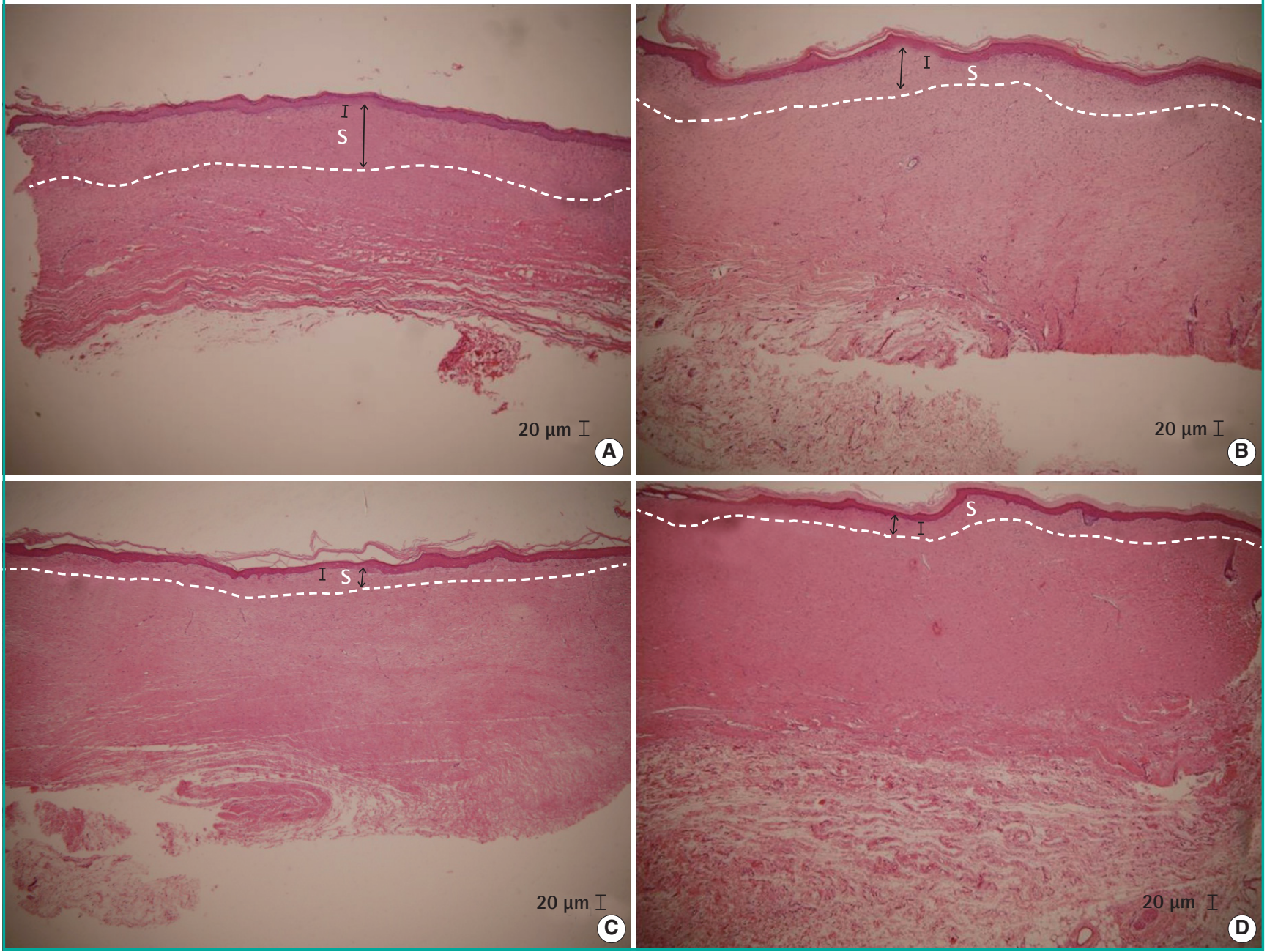
differences between the groups at a given point in time. The thickness of the scar tissue, the statistical differences of a given group among the points in time, and the statistical differences between groups at a point in time were analyzed by one-way ANOVA and multiple comparison using SPPS ver. 19.0 (IBM Corp., Armonk, NY, USA). Multiple comparisons among the points in time and between the groups were analyzed using Tukey's method. A P-value $<0.05$ was considered statistically significant.

\section{RESULTS}

\section{Total epithelialization time and location of each group of rats}

The average of the total epithelialization time and randomized location of each group are presented in Table 1. Until the end of the experiment, none of the rats expired for reasons other than biopsy.

\section{Histologic evaluation}

At week three, histologically, with incomplete tissue reepithelialization, the amounts of scar tissue and inflammatory cells were observed. However, at weeks 10 and 17, with complete epithelialization, mild fibroblastic proliferation, modeled dense collagen mesh, and moderate fibrosis were observed (Fig. 3).

\section{Scar tissue thickness}

The average scar tissue thicknesses and standard deviation for each week for each group are presented in Table 2. In all four groups, the thickness measured at week 10 was significantly decreased, compared with that at week three $(\mathrm{P}<0.05)$. The

Table 2. Mean thickness of scar tissue in the Control, Vaseline, Kelo-cote, and Contractubex groups for each week

\begin{tabular}{|lc|}
\hline Group & Mean \pm standard deviation $(\mu \mathrm{m})$ \\
\hline 3 wk & $212 \pm 8.367$ \\
Control group & $206 \pm 11.402$ \\
Vaseline group & $198 \pm 8.367$ \\
Kelocote group & $196 \pm 8.944$ \\
Contractuvex group & \\
10 wk & $108 \pm 13.038$ \\
Control group & $62 \pm 8.367$ \\
Vaseline group & $22 \pm 8.367$ \\
Kelocote group & $24 \pm 11.402$ \\
Contractuvex group & \\
17 wk & $100 \pm 8.367$ \\
Control group & $58 \pm 8.367$ \\
Vaseline group & $18 \pm 4.472$ \\
Kelocote group & $22 \pm 8.367$ \\
Contractuvex group & \\
\hline
\end{tabular}

thickness measured at week 17 was also significantly decreased, compared with that at week three $(\mathrm{P}<0.05)$. However, no significant differences were observed between the thickness measured at weeks 10 and 17 ( $\mathrm{P}>0.05)$ (Fig. 4).

No significant difference in thickness measured at week three was observed among any of the groups (control, $212 \pm 8.367$; Vaseline, $206 \pm 11.402$; Kelo-cote, $198 \pm 8.367$; Contractubex, $196 \pm 8.944 ; \mathrm{P}>0.05$ ). The thickness measured at week 10, between the Control and the Vaseline groups (control, $108 \pm$ 13.038; Vaseline, 62 \pm 8.367 ; $\mathrm{P}<0.05$ ), between the Control and Kelo-cote groups (control, $108 \pm 13.038$; Kelo-cote, $22 \pm 8.367$; $\mathrm{P}<0.05$ ), and between the Control and Contractubex groups (control, 108 \pm 13.038; Contractubex, 24 \pm 11.402; P <0.05) showed significant differences. The thickness measured at week 17, also, between the Control and the Vaseline groups (control, $100 \pm 8.367$; Vaseline, $58 \pm 8.367 ; \mathrm{P}<0.05$ ), between the Control and Kelo-cote groups (control, $100 \pm 8.367$; Kelo-cote, $18 \pm 4.472$; $\mathrm{P}<0.05$ ), and between the control and Contractubex groups (control, $100 \pm 8.367$; Contractubex, $22 \pm 8.367$; $\mathrm{P}<0.05$ ) showed significant differences.

In addition, at week 10, significant differences were observed between both the Vaseline and Kelo-cote groups (Vaseline, $62 \pm$ 8.367; Kelo-cote, $22 \pm 8.367$; $\mathrm{P}<0.05$ ), and between the Vaseline and Contractubex groups (Vaseline, $62 \pm 8.367$; Contractubex, 24 $\pm 11.402 ; \mathrm{P}<0.05)$. At week 17, also, significant differences were observed between both the Vaseline and Kelo-cote

\section{Fig. 4. Statistical differences in each time and group}

In all four groups, the thickness measured at week three was significantly different from that measured at weeks 10 and 17. However, no significant differences were observed between thicknesses measured at weeks 10 and 17. No significant difference in thickness measured at week three was observed in any of the groups. The thickness measured at weeks 10 and 17 showed a significant difference between the control group and other groups, between the Vaseline group and the Kelo-cote group, and between the Vaseline group and the Contractubex group. However, no significant differences were observed between the Kelo-cote group and the Contractubex group $\left({ }^{*} \mathrm{P}<0.05\right)$.

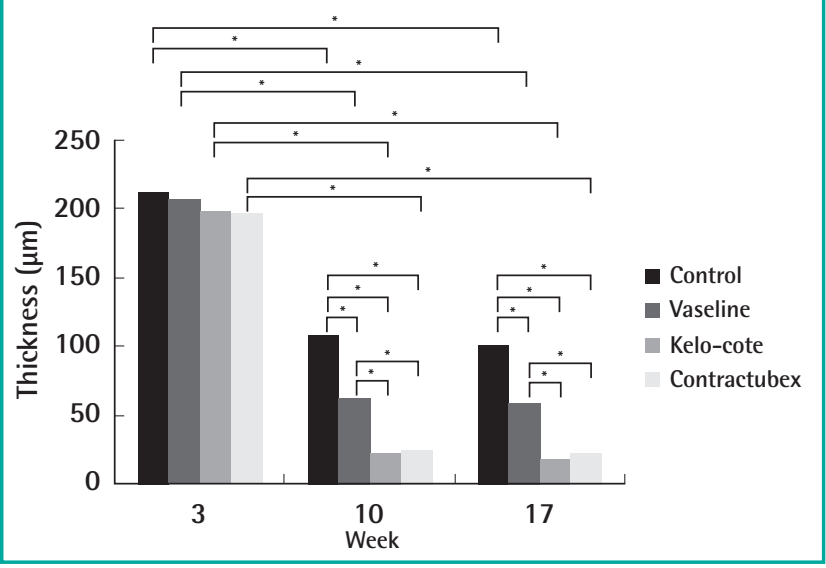


groups (Vaseline, 58 \pm 8.367 ; Kelo-cote, $18 \pm 4.472 ; \mathrm{P}<0.05$ ), and between the Vaseline and Contractubex groups (Vaseline, $58 \pm 8.367$; Contractubex, $22 \pm 8.367 ; \mathrm{P}<0.05)$. However, no significant difference in thickness measured at week 10 or 17 was observed between the Kelo-cote and Contractubex groups (10 weeks, Kelo-cote, $22 \pm 8.367$; Contractubex, 24 \pm 11.402 ; 17 weeks, Kelo-cote, $18 \pm 4.472$; Contractubex, $22 \pm 8.367$; P > $0.05)$ (Fig. 4).

\section{DISCUSSION}

Wound healing is a dynamic, interactive process involving soluble mediators, blood cells, extracellular matrix, and parenchymal cells. Wound healing has three phases-inflammatory, tissue formation, and tissue remodeling, which overlap in time [2]. Niessen et al. [7] differentiated four wound healing phaseshemostasis, inflammatory, granulation, and remodeling. After hemostasis and wound debridement by inflammatory cells, with formation of granulation tissue, repair of the injured dermis begins to occur. The transformation of a wound clot into granulation tissue requires an accurate balance between matrix degradation and matrix biosynthesis for achievement of normal healing. In the remodeling phase, tissue gains tensile strength through collagen remodeling. If a less appropriate orientation of collagen fibers is present in granulation tissue, these collagen nodules serve as a prognostic factor for development of excessive scar tissue, such as hypertrophic scars and keloids $[6,18]$. Scars evolve from granulation tissue that is comparatively rich in cells. Granulation tissue fibroblasts and small vessel cells derive from similar pre-existing cells in the subcutaneous tissue. In addition, it is well established that the evolution of granulation tissue into scar tissue implies a massive decrease in cellularity, notably involving the disappearance of fibroblasts, endothelial cells, and pericytes. When granulation tissue does not evolve into scar tissue properly, the resulting increases in collagen synthesis and decrease in collagen degradation result in the development of pathologic scarring, that is, hypertrophic scars and keloids [3].

Several recent studies have proposed the use of topical silicone gel as the main form of noninvasive treatment for hypertrophic scars and keloids $[5,6,9,10]$. In addition, other studies have demonstrated its effectiveness for prevention of hypertrophic scars and keloids [7,9-11]. Methods for application of silicone gel on scars include coating to the wound, attachment of a silicone gel sheet, and massage with a gel. In this study, among these methods, we performed massage with a topical agent. The effects of silicone gel for prevention of hypertrophic scars and keloids have been variously reported in several studies. de Giorgi et al. [8] reported that only $27 \%$ of patients in the treatment group had formation of nonphysiological scars, whereas 55\% of patients in the control group had altered scars. Silicone gels have been used by Perkins et al. [11] in Australia for treatment of burns since 1982 [12]. Numerous mechanisms have been suggested to explain the efficacy of silicone gel, including hydration, pressure, temperature, oxygen transmission, and silicone absorption. However, although the exact mechanism of action remains unknown, there is some evidence that silicone gel treatment affects the stratum corneum, and by reducing evaporation, restores better homeostasis to the tissue. In hypertrophic scars, the stratum corneum allows for more evaporation of water from the underlying tissue than occurs in normal skin $[10,13]$. Silicone gel prevents this, keeping the stratum corneum in optimal hydration. The gel may also affect the stratum corneum by inhibiting mast cell activity, and diminishing edema, vasodilatation, and excessive extracellular matrix formation [10].

Contractubex contains cepae extract, heparin, and allantoin, and its use has been widespread for more than 30 years. After evaluation of the experimental efficacy and pharmacokinetics of each active ingredient and their combination, clinical studies were conducted in order to prove its safety and efficacy. It has been well evaluated in experimental and clinical studies, and its scar-relevant anti-proliferative effect on fibroblasts and its effect on glycosaminoglycan synthesis have been proven [19]. We also think that the strengthening effect of massage is the same as that of Kelo-cote. Vaseline is a plain petroleum gel; we performed Vaseline massage for comparison with the other groups in order to rule out the pharmacological effect, because bare finger massage can easily cause skin irritation. Therefore, Vaseline was used only as a lubricant ointment and moisturizer.

Recently, the properties of occlusion and hydration are considered important in scar management. Occlusive properties create an environment favoring epidermal hydration and prevent water loss from the underling epidermal layer [7-13]. It has been proven that the occlusion of a topical agent will cause an increase in hydration in the skin responsible for a decrease in capillary activity, reduced hyperemia, and reduced collagen deposition [20,21]. In vitro research has shown that hydration modulates the in vitro keratinocyte-fibroblast interaction. Keratinocytes proved to need a moist environment to down-regulate fibroblast collagen and glycosaminoglycan production [20]. The author's hypothesis is that massage of a topical agent can allow for close apposition of the agent material and the scar. In other words, massage allows for occlusion of the scar, hydration of the skin, and maximization of the gel's effect.

Several recent studies have demonstrated that the effect of massage may shorten the time required for formation of a mature scar [14]. In addition, there is some physiologic evidence 
regarding the effect of massage in that mechanical disruption of fibroblast tissue increases the pliability of the scar [14,22,23]. Mechanical forces induce changes in expression of extracellular matrix proteins and protease, and massage may alter the structural and signaling circumstances. Although the exact mechanism remains to be determined, many results have suggested that massage may be effective through its ability to affect matrix remodeling and fibroblast apoptosis [22-24].

This study is significant for two reasons. First, it is the first study conducted for determination and comparison of the effectiveness of two topical agents, Kelo-cote and Contractubex, by measuring the decrease in the thickness of scar tissue. Second, it is the first study to determine the effectiveness of massage and hydration by occlusive use of topical agent massage on burn scars, not with regard to the relief of pruritus, erythema, and pigmentation [17], but regarding the effect of reducing the thickness of scar tissue.

In our study, we measured the thickness of scar tissue at postmassage 3, 10, and 17 weeks. In all of the groups, the thickness measured at 10 weeks was significantly decreased, compared with that at three weeks. The thickness measured at 17 weeks was also significantly decreased compared with that at three weeks. However, no significant differences were observed between the thickness measured at 10 and 17 weeks. In addition, above 10 weeks, no significant reduction was observed. We observed that normal scar tissue was highly decreased in the early remodeling phase.

In addition, at 10 and 17 weeks, the scar tissue thickness of the Vaseline group was significantly thinner than that of the control group. This finding suggested that massage only with a lubricant had a significant effect on the decrease in scar tissue. The scar tissue thicknesses of the Kelo-cote and Contractubex groups were significantly thinner than those of the Control group. Furthermore, these were significantly thinner than those of the Vaseline group. This finding suggested that other effects as well as massage with hydration influenced the decrease in the scar tissue thickness. This also suggested that the pharmacological mechanism of Kelo-cote and Contractubex had an effect on the decrease in the scar tissue thickness. Therefore, it can be concluded that Kelo-cote and Contractubex massage were significantly effective in decreasing the amount of scar tissue. However, no significant difference was observed between the two groups. In addition, massage using topical agents is more effective in the early remodeling phase. These results support the effectiveness of scar rehabilitation treatment on burn scars in early management.

This study proposes that massage with two topical agents (Kelo-cote and Contractubex) is effective on burn scars; and when a topical agent is not available due to allergies or other reasons, it is suggested that even a simple massage with lubricant can be helpful.

However, in order to fully understand the effect of topical massage, further studies on how cells and mediators influence the amounts of scar tissue are needed in order to provide reliable evidence according to the wound healing mechanism. In addition, we could not demonstrate the hydration effect alone of a topical agent because we did not create an experimental group with just coating of the scar but no massage. To understand the hydration-only effect of topical agents and the effect of massageonly without an agent, further studies comparing just the coating of the agent and topical agent massage are needed.

\section{REFERENCES}

1. Broughton G 2nd, Janis JE, Attinger CE. The basic science of wound healing. Plast Reconstr Surg 2006;117:12S-34S.

2. Singer AJ, Clark RA. Cutaneous wound healing. N Engl J Med 1999;341:738-46.

3. Desmouliere A, Redard M, Darby I, et al. Apoptosis mediates the decrease in cellularity during the transition between granulation tissue and scar. Am J Pathol 1995;146:56-66.

4. Gurtner GC, Werner S, Barrandon Y, et al. Wound repair and regeneration. Nature 2008;453:314-21.

5. Alster TS, Tanzi EL. Hypertrophic scars and keloids: etiology and management. Am J Clin Dermatol 2003;4:235-43.

6. Berman B, Perez OA, Konda S, et al. A review of the biologic effects, clinical efficacy, and safety of silicone elastomer sheeting for hypertrophic and keloid scar treatment and management. Dermatol Surg 2007;33:1291-302.

7. Niessen FB, Spauwen PH, Schalkwijk J, et al. On the nature of hypertrophic scars and keloids: a review. Plast Reconstr Surg 1999;104:1435-58.

8. de Giorgi V, Sestini S, Mannone F, et al. The use of silicone gel in the treatment of fresh surgical scars: a randomized study. Clin Exp Dermatol 2009;34:688-93.

9. Gold MH, Foster TD, Adair MA, et al. Prevention of hypertrophic scars and keloids by the prophylactic use of topical silicone gel sheets following a surgical procedure in an office setting. Dermatol Surg 2001;27:641-4.

10. Momeni M, Hafezi F, Rahbar H, et al. Effects of silicone gel on burn scars. Burns 2009;35:70-4.

11. Perkins K, Davey RB, Wallis KA. Silicone gel: a new treatment for burn scars and contractures. Burns Incl Therm Inj 1983;9:201-4.

12. Mustoe TA. Evolution of silicone therapy and mechanism of action in scar management. Aesthetic Plast Surg 2008; 
32:82-92.

13. O’Shaughnessy KD, De La Garza M, Roy NK, et al. Homeostasis of the epidermal barrier layer: a theory of how occlusion reduces hypertrophic scarring. Wound Repair Regen 2009; 17:700-8.

14. Shin TM, Bordeaux JS. The role of massage in scar management: a literature review. Dermatol Surg 2012;38:414-23.

15. Holavanahalli RK, Helm PA, Parry IS, et al. Select practices in management and rehabilitation of burns: a survey report. J Burn Care Res 2011;32:210-23.

16. Roques C. Massage applied to scars. Wound Repair Regen 2002;10:126-8.

17. Patino O, Novick C, Merlo A, et al. Massage in hypertrophic scars. J Burn Care Rehabil 1999;20:268-71.

18. Linares HA, Larson DL. Early differential diagnosis between hypertrophic and nonhypertrophic healing. J Invest Dermatol 1974;62:514-6.

19. Beuth J, Hunzelmann N, Van Leendert R, et al. Safety and efficacy of local administration of contractubex to hypertro- phic scars in comparison to corticosteroid treatment: results of a multicenter, comparative epidemiological cohort study in Germany. In Vivo 2006;20:277-83.

20. Chang CC, Kuo YF, Chiu HC, et al. Hydration, not silicone, modulates the effects of keratinocytes on fibroblasts. J Surg Res 1995;59:705-11.

21. Davey RB, Wallis KA, Bowering K. Adhesive contact media: an update on graft fixation and burn scar management. Burns 1991; 17:313-9.

22. Chan MW, Hinz B, McCulloch CA. Mechanical induction of gene expression in connective tissue cells. Methods Cell Biol 2010;98:178-205.

23. Bhadal N, Wall IB, Porter SR, et al. The effect of mechanical strain on protease production by keratinocytes. Br J Dermatol 2008;158:396-8.

24. Aarabi S, Bhatt KA, Shi Y, et al. Mechanical load initiates hypertrophic scar formation through decreased cellular apoptosis. FASEB J 2007;21:3250-61. 